\title{
Research on the Construction of Public Service Platform for Integrated Logistics Information in Multimodal Transport
}

\author{
Shijun Yuan \\ Hunan Modern Logistics College \\ Changsha, China 410131
}

\author{
Jianhua Chen \\ Hunan Modern Logistics College \\ Changsha, China 410131
}

\author{
Zhaohui Wang* \\ Hunan Modern Logistics College \\ Changsha, China 410131 \\ *Corresponding Author
}

\begin{abstract}
Starting from the analysis of the necessity of the construction of the public service platform of multimodal integrated logistics information, this paper predicts the radiation driving effect after the construction of the project, and puts forward the main contents and construction scheme of the project, which will provide reference for the buildup of similar projects.
\end{abstract}

Keywords-multimodal transport; information platform; research

\section{INTRODUCTION}

Multimodal transport is an effective link between two or more modes of transport, providing integrated cargo transport services throughout the organization featured by long industrial chain, high utilization rate of funds and good comprehensive benefits. It has an overall objective of deepening structural reform of transport, promoting cost reduction and efficiency improvement of logistics industry as well as green and low-carbon development of transport. Meanwhile, the project aims to serve the country's "three strategies" and regional development. In a word, the project embraces a positive significance and important role.

\section{NECESSITY OF PROJECT CONSTRUCTION}

\section{A. Meeting the Needs of National Policy Development}

Informatization is the trend of world development and an important force to promote economic and social change. China has formulated the National Informatization Development Strategy from 2006 to 2020, which focuses on the transformation and upgrading of traditional industries by using information technology. It's inevitable to make full use of information technology to advance the transformation of high energy consumption, high material consumption and high pollution banks, and boost supply chain management and customer relationship management.

\section{B. Meeting the Needs of Coordinated Development of Various Modes of Transport}

The construction of multi-modal transport information platform assists to avoid the traditional block management mode more effectively and innovate the management method and operation mode of container multi-modal transport, finally completely eliminating the separated state of this kind of transport. Based on the public information service system, an information service network platform of multi-modal transport with unified standards, perfect functions, safety and reliability for the public shall be built to remove the barriers of information transmission among departments, so as to effectively coordinate various modes of transport and rationally allocate transport resources.

\section{Meeting the Needs of Developing Sea-rail Intermodal Transport at Present}

Sea-rail intermodal transport has the advantages of customs declaration in different places, less intermediate links, high punctuality and large transportation volume, which can effectively reduce the time and cost of cargo transporting. As a green and low-carbon transport mode, searail intermodal transport is increasingly welcomed and advocated. Since 2003, China's port container throughput has been ranked first in the world, accounting for more than $40 \%$ of the world's total amount. For such a huge port container collection and distribution, the road undertakes about $84 \%$, water-water intermodal undertakes $14-15 \%$, and sea-rail intermodal undertakes no more than $1.5 \%$. In contrast, for Europe and the United States container ports, sea-rail intermodal transport accounts for $20-30 \%$.

\section{Meeting the Needs of Reducing Logistics Cost of Multimodal Transport}

At present, more than $80 \%$ of domestic cargo transportation still relies on road transportation, while the 
network transport capacity between highway, railway, water transport and air transport is poor, which leads to high logistics costs. The cost of domestic logistics industry accounts for about 2 times of the GDP of developed countries. Consequently, the high cost of logistics weakens the overall competitiveness of China's industrial manufacturing industry and restricts the development of national economy. Through information public service platform of the multi-modal transport logistics project, enterprises such as logistics groups and industrial manufacturing industries can be seamlessly linked up to form alliances, changing the status quo of logistics enterprises in large, small and scattered state. By improving the matching degree of transportation resources and goods sources, the level of intensity, scale and specialization of multimodal transport will be improved; the efficiency of multimodal transport can also be effectively improved; and the total cost of social logistics can be effectively reduced.

\section{PREDICTION OF RADIATION-DRIVEN EFFECT AFTER PROJECT CONSTRUCTION}

\section{A. Integrating Logistics Resources and Improving the Basic Conditions for the Development of Logistics Industry in the Region}

The establishment of this project helps to connect different information platforms of transportation, logistics transaction and related government department, so that the functions of each system can be better played. Meanwhile, through the development and application of various valueadded functions such as analysis and statistics, the vast amount of information can be transformed into that used for decision support. For enterprises, it can produce enormous economic benefits by improving efficiency, rational use of resources, timely and effective planning and management; for relevant government departments, through certain authorization, it can timely understand the relevant information of transportation industry, an integral part of national economy, so as to help formulate effective policies for rational macro-control and guidance; for users, through this way, the establishment of the system enables users to timely know about the situation of cargo transportation, improve the satisfaction of the transport enterprises, finally increasing the supply of cargo continuously.

\section{B. Improving the Operating Benefits of Logistics Enterprises}

The economic benefit or profit of logistics enterprises comes from the balance between the charge of logistics service and the actual cost of it provided by enterprises. The greater the market demand for logistics services, and the stronger the sales volume of logistics enterprises, the better the economic benefits of enterprises will be; the lower the actual cost of logistics services, the more profitable the enterprises will be.

Based on the openness and expansion of the Internet, the construction of logistics public information platform can stimulate the demand of logistics consumption to varying degrees and reduce the logistics cost of enterprises. Firstly, timely and effective information communication channels have been established among logistics enterprises, cargo owners and logistics enterprises, so that various logistics service functions are capable of being centralized, so that logistics service consumers are allowed to find logistics services that can meet their own needs, improve service quality and increase customer satisfaction, invisibly improving the competitiveness of the logistics industry and expanding customer demand for logistic. Secondly, public information platform enjoys the ability to centralize logistics enterprises and logistics resources (such as logistics technology, talents, information, facilities, development and design, etc.), which are geographically dispersed, making it possible for the large-scale and networked operation of the industry. Thirdly, the platform provides management system corresponding to the whole process of logistics (including warehousing, transportation, distribution, etc.), which shortens the service cycle, improves the logistics efficiency and reduces the logistics service cost of enterprises. Fourthly, the use of automated equipment to collect and process information generated in the process of business flow and logistics maximizes the analysis and mining of existing information to guide and manage logistics activities, so that logistics enterprises are able to provide personalized and differentiated services according to the needs of customers, thereby improving the profits of enterprises

\section{Project CONSTRUCTION CONTENT AND SCHEME}

\section{A. Main Construction Contents}

This project plans to construct multimodal transport information data center, including service and data exchange and sharing platform, large data analysis and application platform, cross-border e-commerce intermodal transport service center, Internet one-stop integrated service center, logistics seminar and conference center, commodity detection and monitoring center, computer room equipment center, office service center, etc. to dock freight logistics services and commodity trading suppliers and demanders Moreover, the project will connect highway, railway, water transport, aviation, electronic ports, customs, commodity inspection and other data. By using big data analysis and application of artificial intelligence innovation, the convergence and integration of logistics, business flow, capital flow and information flow can be realized.

The platform integrates parks, multimodal transport enterprises, logistics enterprises, suppliers, demanders, drivers, logistics and service-based applications to help enterprises upgrade the supply chain level. Through industrial linkage, it helps growing third-party logistics enterprises to develop professionally. At the same time, through the optimization of the whole supply chain, the intelligent "logistics cloud" can also converge lag sources in the logistics industry to promote the growth of small and medium-sized logistics enterprises by large and mediumsized ones, so that the overall level of logistics will be ameliorated, and a benign development of the industry will occur. 
1) Overall design of Internet logistics information public service platform of multimodal transport: There are four important content flows in the process of commodity circulation, namely logistics, business flow, information flow and capital flow. On the one hand, information flow is accompanied by business flow, on the other hand, it plays an important role in guiding the regular movement of logistics. It is an important basis for analyzing business flow, guiding capital flow and making business decisions. In the process of multimodal transport, how to manage the direction of information flow well and deal with the information of every link in multimodal transport correctly and timely is the key to the construction of Yueyang multimodal transport Internet logistics information public service platform.

2) Construction target of Internet logistics information public service platform for multimodal transport: It will be responsible for jointing multi-modal supply chain freight logistics services and commodity trading suppliers and demanders all-round, connecting data such as highway, railway, water transport, aviation, electronic ports, customs, commodity inspection and so on followed by innovating big data analysis and application using artificial intelligence to realize the integration and exchange of logistics, business flow, capital flow and information flow.

3) Overall structure of public service platform for multimodal transport Internet logistics information: On the basis of fully considering the openness, integration, practicability, advancement, reliability and economy of the system, the architecture of the information system is formed according to the construction requirements of the overall objective of the system.

\section{B. Construction Plan}

1) Multimodal transport logistics information data center: Multimodal transport information data center, including service and data exchange and sharing platform, large data analysis and application platform. According to the survey by the China Federation of Logistics and Purchasing, the ratio of goods to vehicles in China has reached 6:1, and the transportation capacity is far from meeting the requirements. However, the empty return rate of Chinese logistics drivers is as high as $40 \%$, and the empty return rate in the western region is higher. Almost all the logistics parks have planned a huge display trading hall with investment of tens of millions at the beginning of construction, but few drivers view large-screen information, which is due to the uncertainty of drivers' return journey and the inconvenience of roundabout inspection in large-scale park. How to make the distribution information available to truck drivers simple and efficient is the primary problem that the government urgently needs to solve. It is also the fastest way to reduce logistics cost by means of information technology.
It's necessary to provide a variety of convenient means such as short message, WAP Internet access, special terminal, 114 dialing to get information of goods to be transported at anytime and anywhere. Logistics common application group is the connection center and its main function is to connect the enterprise information platform and information system, so as to provide business services for enterprises. The main functions include logistics e-commerce, software rental, fourth party logistics and communication services etc.

For the small and medium-sized customers in Yueyang and its surrounding areas, this project constructs a logistics trading platform, which provides matching transaction and agent logistics service. It can intelligently match logistics enterprises according to customers' needs for transactions, and can also be handed over to the third party logistics enterprises for transportation after taking over business by our company. In the process, the platform assumes the role of matchmaker or car-free carrier.

2) Cross-border e-commerce and industry intermodal service center: Cross-border e-commerce and industry intermodal transport service center relies on the intermodal transport connecting cross-border e-commerce and industry intermodal transport service subsystem, aiming at crossborder e-commerce, cold chain logistics (meat port), hazardous chemicals logistics (100 billion industries), agricultural products logistics (100 billion industries) and other logistics industries with special requirements. This platform has developed the intermodal transport service system to achieve the whole process supervision, safety guarantee and quality control. The cold chain logistics transportation monitoring system provides a comprehensive and efficient solution for the vehicle and temperature monitoring of refrigerated goods in the transportation process. The system functions include vehicle tracking, temperature control, alarm processing, vehicle information query, cargo information query, user management, system management, etc.

3) Internet one-stop integrated transport service center: Internet One-stop Integrated Transport Service Center relies on the characteristics of Internet One-stop Integrated Transport Business to develop an integrated management system to provide integrated transport services. Its task is to grasp the dynamics of logistics supply chain in real time, from goods order to shipment, to the coordination of a series of links controlled by logistics companies, and then to deliver goods to the consignee. System functions include order management, scheduling management, tracking management, return management, statistical analysis, financial accounting, resource management, system maintenance and so on.

4) Multimodal transport office integrated service center: The multi-modal transport office integrated service area constructs logistics seminar and conference center, office service center, commodity inspection and monitoring center, and provides multi-modal transport supply chain integrated office services. 
5) Computer room equipment center: On the basis of meeting the equipment allocation of the above-mentioned construction contents, the equipment center of the computer room is equipped with the functions of data docking and sharing between multimodal transport and warehousing, large data analysis of multimodal transport, innovative research and application of multimodal transport data, data integration and exchange, etc.

\section{CONCLUSION}

Multimodal transport has been upgraded to the national strategic level, and the construction of integrated information platform for multimodal transport is the key to the efficient operation of multimodal transport. This paper provides a very good reference for the construction of integrated logistics information platform for multimodal transport.

\section{REFERENCES}

[1] Lai Fei, Zhang Yi. Analysis and Elaboration of the Construction Mode of Port Multimodal Transport Information Platform [J].China Management Informationization. 2016(20). (in Chinese)

[2] Zhu Youwen. Research on the Construction of Public Information Platform for Container Multimodal Transport [J].Railway Freight Transport. 2010(11) (in Chinese)

[3] Liu Yongbo, Daijun. Research on Information Resource Integration Technology in Cloud Computing Environment [J].Computer CD Software and Application. 2012(08). (in Chinese). 